\title{
Properties of Rf Plasma Nitrided Silicon Thin Films at Different Rf Plasma Processing Powers
}

\author{
S.H. Mohamed ${ }^{a, b}$, M. RAAif $^{b}$, A.M. Abd El-Rahman ${ }^{b}$ And E.R. ShaAban $^{a, c}$ \\ ${ }^{a}$ Physics Department, College of Science, Qassim University, P.O.B. 6644, 51452, Buryadh, Kingdom of Saudi Arabia \\ ${ }^{b}$ Physics Department, Faculty of Science, Sohag University, 82524 Sohag, Egypt \\ ${ }^{c}$ Department of Physics, Faculty of Science, Al-Azahar University, Assiut, 71542, Egypt
}

(Received January 19, 2011; in final form May 31, 2011)

\begin{abstract}
Nitrided surfaces and composition gradients in thin films exhibit interesting mechanical, electrical and optical properties. Therefore, silicon ( $\mathrm{Si}$ ) thin films were prepared by electron beam evaporation and nitrided by an inductively coupled rf plasma. The effects of successive plasma processing power on structural and optical properties as well as electrical resistivity were examined by different characterization techniques. The Si thin films were transformed gradually into nitrides compound thin films and the amount of nitrogen in the film increased with increasing the rf processing power. The Si nitrided films showed structural, optical and electrical properties that depend on the nitriding power. Increasing the rf plasma processing power caused amorphization, reduced the thickness, increased transmittance, increased resistivity and decreased the reflectance of the Si films. The electrical resistivity increased about eight orders of magnitude when the sample nitrided at $500 \mathrm{~W}$. Different optical band gap were determined indicating the presence of different competing phases in the same film. The decrease in refractive index with plasma treatment power is attributed to the possible change in the bucking density as well as to the increase in the band gap.
\end{abstract}

PACS: 81.15.Dj, 61.05.cp, 73.61.-r, 78.66.-w

\section{Introduction}

Silicon thin films are currently used in different technological areas such as photovoltaic cells [1, 2], thin-film transistors [3], microelectromechanical systems [4], and Li-ion rechargeable batteries [5]. On the other hand, silicon dielectrics are important materials for both microelectronics and integrated optics. In particular, silicon dielectrics have been considered as an appropriate material for fabricating optical waveguides in broadband communications (telecom and datacom) [6-8].

The effects of ions, electrons, and other energetic particles are now widely utilized for substrate cleaning as well as to assist and control film growth. Some of the particles are not just assisting but they may condense and thereby become part of the growing film [9]. The role of nitrogen plasma-surface reactions is very important in various phenomena of technological interest such as corrosion, surface functionalization, and thin film growth. Inductively coupled radio frequency (rf) discharges have proven technological significance, for surface modification, fabrication of modern integrated circuit devices, and thin film deposition $[10,11]$. The great majority of fundamental studies involve the interaction between nitrogen plasma species and solid surfaces, but there is a lack of specific correlation between optoelectronic properties and plasma parameters.
Nitriding of silicon has been often produced by using electron cyclotron resonance nitrogen plasma [12], heating silicon in an atmosphere of nitrogen at elevated temperatures [13], ion beam nitridation [14], low energy nitrogen ion implantation [15], ion-beam-enhanced deposition [16], stable discharging of pure nitrogen maintained between two parallel plate electrodes [17], inductively coupled nitrogen plasma [18], etc. Nitrides of Si carried out by rf plasma nitriding or similar means have been contemplated for use as metal-oxide-semiconductor field effect transistors [18], oxidation barriers [16, 19], gate insulators [15], optical coatings [20], and silicon-on-insulators [21].

There is a number of plasma process parameters which could affect the resulting properties of the treated surface such as electrode temperature, plasma pressure, rf plasma processing power, rf plasma processing time, etc. One of the most effective parameters is the plasma processing power. The amount of power applied to a plasma system affects several plasma parameters such as electrode temperature. As power increases, greater ion energies are obtained further enhancing etching due to ion bombardment $[22,23]$. Thus, the aim of the study described herein is to plasma nitride silicon thin films using inductively coupled rf plasma nitriding and to examine the effectiveness of the plasma nitriding process as a function of the nitriding variable of rf plasma processing power. 


\section{Experimental details}

Si thin films were prepared by electron beam evaporation in an Edward high vacuum coating unit, model $30 \mathrm{~A}$, which had a base pressure of $6.55 \times 10^{-4} \mathrm{~Pa}$. The evaporation was carried out from cold pressed Si tablet, which had been previously compressed from Si powder of $99.9 \%$ purity (Aldrich Chemicals). The Si powder was previously stored in the laboratory and subjected to air atmosphere for more than two years. The evaporation process was started after achieving high vacuum of $6.55 \times 10^{-4} \mathrm{~Pa}$. The films were prepared on ultrasonically cleaned microscopic glasses and mirror polished polycrystalline titanium substrates held at room temperature. The substrates had dimensions of $1.2 \times 1.8 \mathrm{~cm}^{2}$. During evaporation, the thickness of the films was controlled using digital film thickness monitor model TM 200 Maxtek to be $\approx 1600 \mathrm{~nm}$. The film deposition rate was $4.2 \pm 0.5 \mathrm{~nm} / \mathrm{s}$.

The effect of rf plasma power was studied at different plasma powers of 350,400, 450 and $500 \mathrm{~W}$. For each power, the film was exposed to nitrogen plasma for $10 \mathrm{~min}$ and then cooled down to room temperature. The rf plasma system has been described elsewhere [24]. In brief, the system comprises a quartz reactor tube with a $500 \mathrm{~mm}$ long and a diameter of $41.5 \mathrm{~mm}$. The tube was evacuated to a base pressure of $2 \mathrm{~Pa}$ by a two-stage rotary pump. The samples are mounted on a water-cooled copper sample holder $(3.6 \mathrm{~cm}$ in diameter) located at $4 \mathrm{~cm}$ from the rf external copper coil. Nitrogen $\left(\mathrm{N}_{2}\right)$ was introduced to establish a gas pressure of 8.4 Pa and measured by means of a capacitance manometer. The induction copper coil, energized by an rf power generator model HFS $2500 \mathrm{D}$ at $13.65 \mathrm{MHz}$ via a tunable matching network, generated the discharge. The increasing sample temperature was measured during the rf plasma process by a chromel-alumel thermocouple which was attached to the sample holder. The temperature of the sample takes up to 2-3 min to attain a steady value for each plasma power input.

The chemical composition and thickness of the rf plasma nitrided Si films was analyzed for the samples prepared on titanium substrates using energy dispersive analysis of X-ray (EDAX, Philips XL 30 scanning) and Dektak IIA profilometer, respectively. The crystallinity of the as-prepared and the nitrided films were examined using a Bucker AXS-D8Advance X-ray diffractometer. $\mathrm{Cu} K_{\alpha}$ radiation $(\lambda=1.5406 \AA)$ was used with normal focus. The optical transmittance $(T)$ and reflectivity $(R)$ of the as-prepared and the nitrided films were measured using a Jasco 570 double beam spectrophotometer in the wavelength $(\lambda)$ range of $200-2500 \mathrm{~nm}$ at normal incidence. The room temperature resistivity measurements were carried out using the two-terminal configuration by applying a constant voltage of $10 \pm 0.1 \mathrm{~V}$ to the sample and measuring the flowing current through it using a Keithley 614 electrometer. Electrical contacts were made by applying silver paste over part of the film surface, in coplanar configuration, with a separation dis- tance of $2 \mathrm{~mm}$. The measurements were performed in dark environment and at atmospheric air.

\section{Results and discussion}

\subsection{Structural properties}

\subsubsection{Film composition and thickness}

The chemical compositions of the as prepared and rf plasma nitrided films are listed in Table as functions of rf plasma processing power. The chemical composition of the as-prepared film is $\mathrm{SiO}_{0.39 \pm 0.06}$. The $\mathrm{N} / \mathrm{Si}$ atomic ratio increases with increasing the rf plasma processing power. However, the oxygen contamination ratio $(\mathrm{O} / \mathrm{Si})$ decreases slightly, then it remains almost constant. The presence of oxygen contamination my arise from the oxidation of some Si powder by air exposure, the residual water in the coating unit's jar and the adsorbed oxygen or the hydroxyl molecules on the surface of the film after it got out of the evaporation chamber or rf plasma reactor tube.

TABLE

The chemical compositions and optical band gap of the as prepared and rf plasma nitrided Si films.

\begin{tabular}{c|c|c|c|c}
\hline \hline \multirow{2}{*}{$\begin{array}{c}\text { Rf power } \\
\text { [W] }\end{array}$} & $\begin{array}{c}\text { Chemical composition } \\
\mathrm{SiO}_{x} \mathrm{~N}_{y}\end{array}$ & \multicolumn{3}{|c}{$E_{\mathrm{g}}[\mathrm{eV}]$} \\
\cline { 3 - 5 } & $\mathrm{SiO}_{0.39}$ & - & - & - \\
\hline As-prep. & $\mathrm{SiO}_{0.37} \mathrm{~N}_{0.13}$ & 2.56 & 2.21 & 3.67 \\
400 & $\mathrm{SiO}_{0.36} \mathrm{~N}_{0.25}$ & 2.19 & 1.88 & 3.72 \\
450 & $\mathrm{SiO}_{0.36} \mathrm{~N}_{0.49}$ & 2.29 & 2.04 & 3.85 \\
500 & & & &
\end{tabular}

Nitrogen can be incorporated into Si using nitridation by energetic rf nitrogen plasmas $[7,18]$. This nitridation method can be performed at low temperatures $\approx 25-500^{\circ} \mathrm{C}$ [7]. As the surface of the Si film is subjected to nitrogen plasma, the nitrogen ions are incorporated into the surface region. Some of the nitrogen ions are diffused into the bulk of the film. The atomic displacements due to collisions may largely improve the nitrogen diffusivity, allowing the material to tend rapidly to equilibrium, which is the formation of the silicon nitride. As long as the plasma exposure power is increased the thickness of the nitrided layer increased and the number of the uncoordinated $\mathrm{Si}$ is decreased.

Figure 1 shows the variation of film thickness as a function of treatment power. The film thickness is drastically reduced from $1610 \mathrm{~nm}$ to $1393 \mathrm{~nm}$ after exposing it to nitrogen rf plasma power of $400 \mathrm{~W}$. By raising the treatment power, the thickness gradually decreases to $1121 \mathrm{~nm}$ for sample treated at $500 \mathrm{~W}$. This reduction in thickness can be ascribed to plasma etching. The change in thickness depends also on the way of density change (in the present case from silicon or silicon oxide to silicon nitride or silicon oxynitride). As the density of $\mathrm{Si}\left(2.33 \mathrm{~g} / \mathrm{cm}^{3}\right)$ is lower than the density of silicon nitride $\left(3.44 \mathrm{~g} / \mathrm{cm}^{3}\right)$ and under the same area of the film, the thickness may decrease due to the increase in density. 


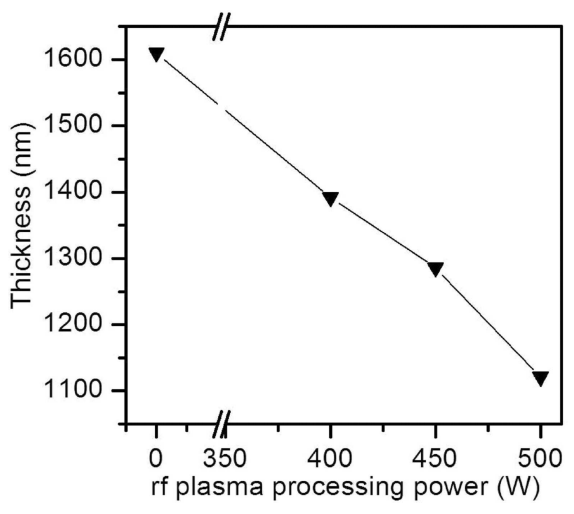

Fig. 1. The variation of film thickness as a function of rf plasma processing power.

\subsubsection{XRD examination}

Figure $2 \mathrm{a}-\mathrm{d}$ shows the X-ray diffraction patterns for $\mathrm{Si}$ films nitrided for different plasma powers. All the patterns reveal the existence of polycrystalline Si structure (JCPDS card no. 41-1111). The as-prepared film (Fig. 2a) has diffraction peaks at $34.76^{\circ}, 36.62^{\circ}, 40.21^{\circ}$, $42.55^{\circ}, 47.89^{\circ}, 61.82^{\circ}$ and $68.60^{\circ}$ indicating a polycrystalline structure. Upon treating the film with nitrogen plasma at $400 \mathrm{~W}$, the yield intensities of peaks around $36.62^{\circ}, 40.21^{\circ}, 42.55^{\circ}, 47.89^{\circ}, 61.82^{\circ}$ and $68.60^{\circ}$ are decreased; however the intensity of the peak around $34.76^{\circ}$ is increased. The further increase in the rf processing power to $450 \mathrm{~W}$ then to $500 \mathrm{~W}$ leads to amorphous structure. It is worthy to mention that there are four major effects inherent in the plasma surface nitridation treatment. One is the surface modification (surface cleaning), the second is surface plasma annealing, the third is the surface chemistry changing (surface composition change) and the last is ion bombardment. The surface plasma cleaning and annealing may enhance the crystallinity, however the surface chemistry changing and the ion bombardment deteriorate the crystallinity. Thus, the observed amorphization at higher plasma processing powers is related to the surface chemistry changes and to the ion bombardment effects. This effect is similar to that of ion implantation at low temperature [25].

\subsection{Electrical resistivity}

The variation of room temperature resistivity with treatment power is shown in Fig. 3. It can be seen that the as-prepared Si film has a very low resistivity of $1.45 \times 10^{-3} \Omega \mathrm{cm}$. Upon rf plasma treatment at $400 \mathrm{~W}$, the resistivity increased to $2.79 \Omega \mathrm{cm}$. The further increase in plasma treatment power to $450 \mathrm{~W}$ then to $500 \mathrm{~W}$ increases the resistivity drastically to $4.28 \times 10^{3} \Omega \mathrm{cm}$, then to $2.42 \times 10^{6} \Omega \mathrm{cm}$. The increase in resistivity is ascribed to: (i) the possible formation of the silicon nitride (that is a dielectric material with resistivity in the range $10^{10}-10^{14} \Omega \mathrm{cm}[26,27]$ ), (ii) the reduction in un-coordinated $\mathrm{Si}$ that provides the carriers [27], and (iii) the nitridation-induced lattice defects, which act as electron scavengers.

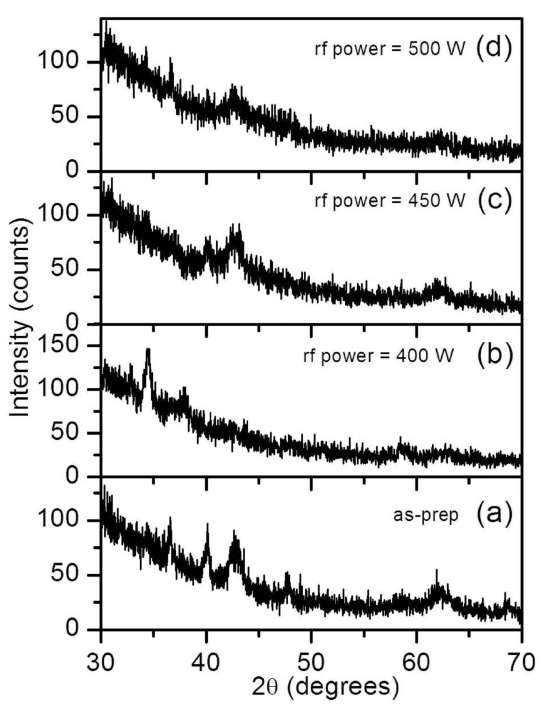

Fig. 2. The X-ray diffraction patterns for Si films nitrided at different plasma powers.

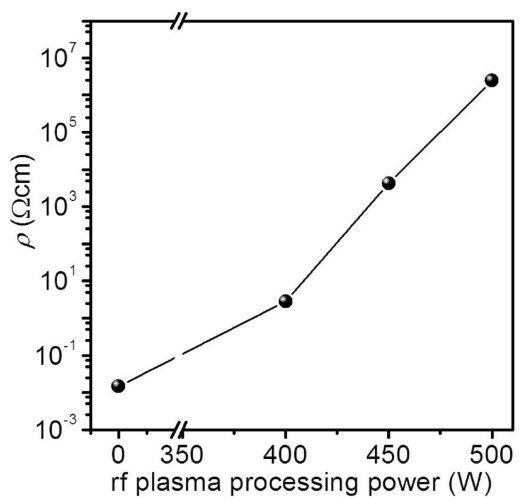

Fig. 3. The variation of room temperature resistivity with treatment power.

\subsection{Optical properties}

The wavelength dependence of optical transmittance and reflectance spectra of the Si films plasma treated at different powers are shown in Fig. 4a and b, respectively. It is observed that the transmittance of the as prepared film is almost zero while the reflectance is very high. This low transmittance and high reflectance is ascribed to the oxidation of some of the silicon atoms and the formation of $\mathrm{SiO}_{x}$ (with $x=0.39 \pm 0.06$ ) which has low transmittance [28]. Treating the films at $400 \mathrm{~W}$, reduces the reflectance strongly and increases the transmittance. The transmittance increases and the reflectance decreases with further increase in rf treatment power. The increase in transmittance and the decrease in reflectance could be related to: the change in the film chemical composition (the formation of the highly transparent silicon nitride and silicon oxynitride), the reduction of the defect centres via plasma surface cleaning, and (iii) the decrease in the films thickness. 


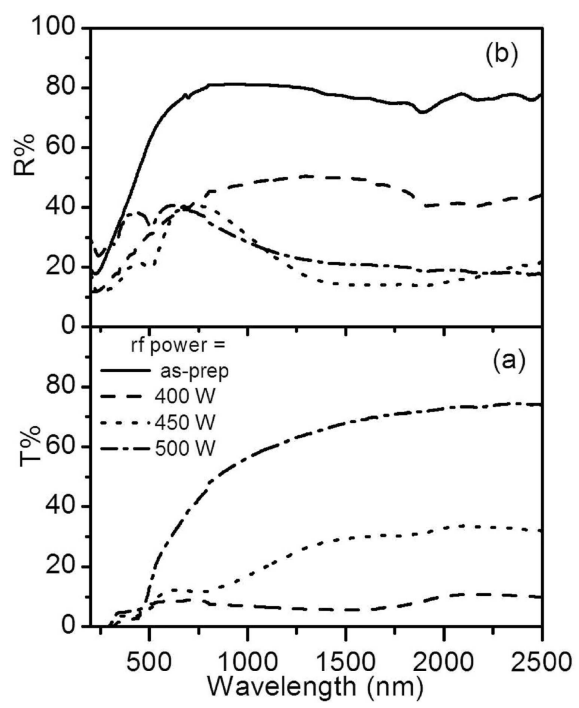

Fig. 4. Wavelength dependence of optical transmittance (a) and reflectance (b) spectra of the Si films treated at different powers, respectively.

The absorption coefficient $(\alpha)$ was evaluated from the experimental data of transmittance and reflectance using the equation

$$
\alpha=\frac{1}{d} \ln \left(\frac{1-R}{T}\right) .
$$

The $\alpha$ values of all the films are found to be greater than $10^{4} \mathrm{~cm}^{-1}$.

The optical band gap $\left(E_{\mathrm{g}}\right)$ values were obtained from the plot of $(\alpha h \nu)^{2}$ versus $h \nu$. It has been found that all the plasma treated films have three direct transitions which corresponding to three different energy gaps. The three regions of $(\alpha h \nu)^{2}$ versus $h \nu$ are fitted separately with solid, dashed and dotted lines as shown in Fig. 5. The obtained band gap values $\left(E_{\mathrm{g} 1}, E_{\mathrm{g} 2}\right.$ and $\left.E_{\mathrm{g} 3}\right)$ are listed in Table. This indicates that there are mixed phases such as silicon, silicon oxynitride and/or silicon oxide and silicon nitride.

It is well known that the $E_{\mathrm{g}}$ values of silicon depend on the preparation methods as well as preparation conditions. However, there exist ambiguities about the band gap of nanocrystalline silicon film. The band gap of hydrogenated amorphous silicon is in the range $1.65-1.78 \mathrm{eV}[29,30]$ whereas band gap of polycrystalline silicon has been found near to the band gap of crystalline silicon $(\approx 1.12 \mathrm{eV}$, bulk value [31]). However, in case of mixed phase of crystalline and amorphous, i.e. nanocrystalline phase, band gap should lie between amorphous and crystalline depending upon the phase fractions [31-33]. In nano/microcrystalline silicon, optical properties are greatly influenced by ratio of volume fraction of crystalline and amorphous phase and also by the hydrogen content in the film. Excluding the effect of hydrogen, band gap broadening could occur in the materials if quantum size effect prevails. Otherwise, many other

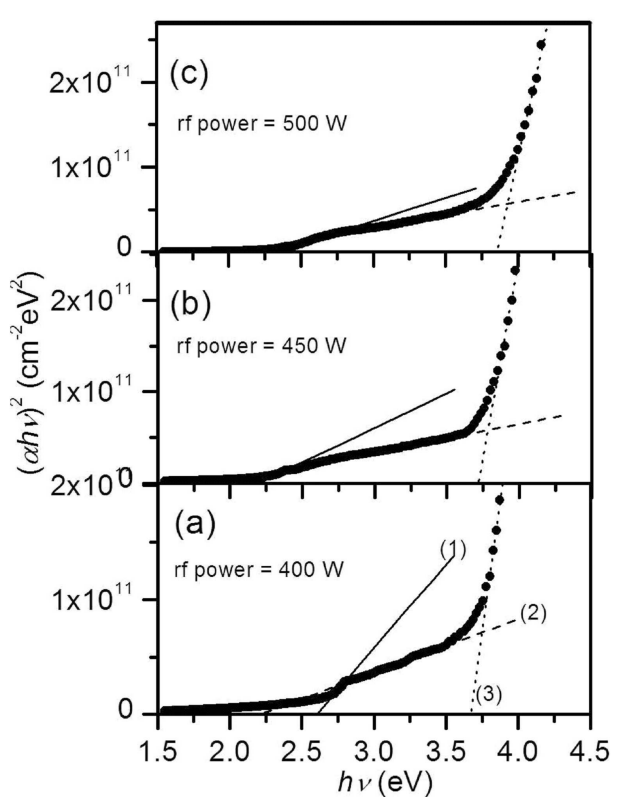

Fig. 5. Plot of $(\alpha \mathrm{h} \nu)^{2}$ versus $h \nu$ for Si films treated at different rf plasma processing powers.

parameters must be looked for the justification of band gap broadening. Surface effects may also play role in the band gap estimated by transmission and reflection method. Insertion of oxygen and/or nitrogen into the silicon matrix could produce the change of band gap as a result of changing the chemical composition (transformation to silicon oxide, silicon nitride or silicon oxynitride).

The optical band gap of $\mathrm{SiO}_{x}$ films depend on the $x$ value. The optical gap of the $\mathrm{SiO}_{x}$ films increased from 1.7 to 2.5 with increasing $x$ in $\mathrm{SiO}_{x}$ from 0.47 to 0.95 [34]. As the $x$ increased to reach a value close to 2 the optical gap increased to reach values greater than $6 \mathrm{eV}$ [28].

Also, the $E_{\mathrm{g}}$ values of silicon nitride depend on the preparation methods, preparation conditions, ratio $\mathrm{N} / \mathrm{Si}$, etc. Low $E_{\mathrm{g}}$ values (2.8 to $4.0 \mathrm{eV}$ ) are obtained using low pressure chemical vapor deposition [35]. Also, low $E_{\mathrm{g}}$ values [36] are obtained for the films containing higher amounts of $\mathrm{Si}$ while $E_{\mathrm{g}}$ values close to the bulk value $(5.0 \mathrm{eV})$ are obtained when the chemical composition of the silicon nitride films is close to the stoichiometric $\mathrm{Si}_{3} \mathrm{~N}_{4}[36,37]$. Based on the above discussion it can be concluded that the increase in $E_{\mathrm{g} 3}$ values with increasing rf plasma processing power may be ascribed to the change in chemical composition of the films toward the nitride side.

Figure 6 shows the variation of refractive index $(n)$ as a function of wavelength of films treated at different rf plasma processing powers. The variation of $n$ with wavelength is very similar to that obtained for the plasma nitrided zirconium films [38]. The $n$ values for the film treated at $400 \mathrm{~W}$ are very high indicating the presence of a significant content of silicon atoms which dramatically increases the refractive index. The refractive index 


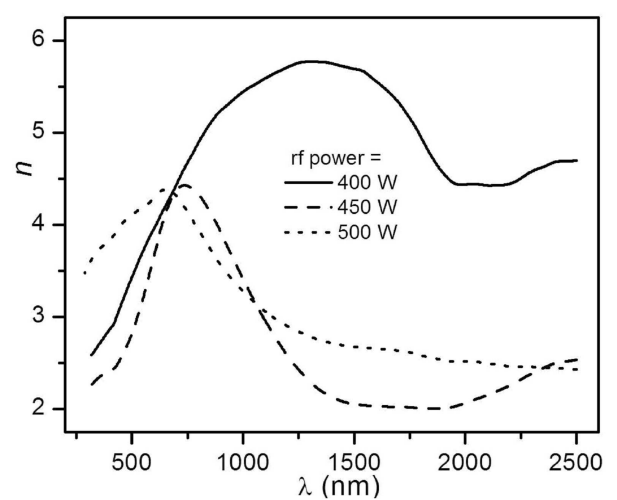

Fig. 6. Variation of refractive index as a function of wavelength for Si films treated at different rf plasma processing powers.

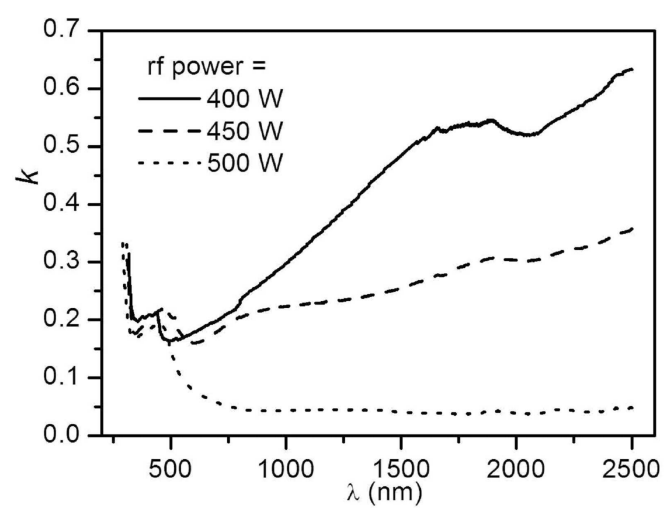

Fig. 7. Variation of extinction coefficient as a function of wavelength for Si films treated at different rf plasma processing powers.

of the films decreases with increasing treatment power. The variation of refractive index may be attributed to the change in the packing density as well as to the increase in the optical band gap with treatment plasma power i.e. N/Si atomic ratio [39]. Verlaan et al. [39] have recently reported, for more than 13 previous works, that the change in refractive index (at $632 \mathrm{~nm}$ ) of $\mathrm{SiN}_{x}$ cannot determine the change in $\mathrm{N} / \mathrm{Si}$ atomic ratio but the change in the optical band gap should be taken, also, into account. Thus, the decrease in refractive index with increasing $\mathrm{rf}$ power is attributed to both the changes in chemical composition and the optical band gap [39].

The extinction coefficient also decreases with increasing treatment power (Fig. 7). The $k$ values are very close to zero for the films treated at $500 \mathrm{~W}$. The variation of the extinction coefficient is directly related to the optical transmittance of the films as shown in Fig. 4a. This decrease in the $k$ values with increasing rf processing power may be ascribed to the reduction of some defect centers which cause absorption and thereby decrease the $k$ values.

\section{Conclusions}

The effects of nitriding using different rf plasma processing powers on the properties of Si thin films, prepared by electron beam evaporation, were studied. The film thickness decreases due to plasma etching and density variation. The incorporation of nitrogen in the Si thin films was insured by EDAX and it was found to increase with increasing rf processing power. The nitrogen incorporation into polycrystalline Si films reduces the diffraction intensity at lower treatment powers and causes amorphization of the films at higher treatment powers. As the nitrogen incorporated in the films the resistivity increased drastically. The extinction coefficient and the refractive index decreased with rf plasma treatment power. The decreasing refractive index with increasing rf plasma processing power is likely to be caused by an increase of the band gap $\left(E_{\mathrm{g} 3}\right)$ as well as by a change in the bucking density. This study showed that it is possible to transform Si thin films gradually into nitrides compound thin films, as important materials for both microelectronics and integrated optics such as thin windows for biomedical microdevices [40], blocks for integration of $\mathrm{rf}$ devices [41] and microelectromechanical systems [42], by controlling the rf plasma processing power.

\section{Acknowledgments}

Prof. Dr. F.M. El-Hossary is acknowledged for his technical support and fruitful discussions. The authors thank Sabic Company through the Deanship of Scientific Research at Qassim University for financial support under contract no. SR-S-009-06.

\section{References}

[1] I. Gordon, S. Vallon, A. Mayolet, G. Beaucarne, J. Poortmans, Solar Energy Mater. Solar Cells 94, 381 (2010).

[2] L. Zhao, Y.H. Zuo, C.L. Zhou, H.L. Li, H.W. Diao, W.J. Wang, Solar Energy 84, 110 (2010).

[3] M. Modreanu, M. Gartner, C. Cobianu, B. O'Looney, F. Murphy, Thin Solid Films 450, 105 (2004).

[4] J.P. Conde, J. Gaspar, V. Chu, Thin Solid Films 427, 181 (2003).

[5] H. Guo, H. Zhao, C. Yin, W. Qiu, Mater. Sci. Eng. B 131, 173 (2006).

[6] M.C. Netti, M.D.B. Charlton, G.J. Parker, J.J. Baumberg, Appl. Phys. Lett. 76, 911 (2000).

[7] K.C. Mohite, Y.B. Khollam, A.B. Mandale, K.R. Patil, M.G. Takwale, Mater. Lett. 57, 4170 (2003).

[8] F. Ay, A. Aydinli, Opt. Mater. 26, 33 (2004).

[9] A. Anders, Surf. Coat. Technol. 200, 1893 (2005).

[10] M.A. Lieberman, A. Lichtenberg, Principles of Plasma Discharges and Materials Processing, Wiley-Interscience, New York 1994.

[11] T. Makabe, Z. Lj. Petrovic, Plasma Electronics: Applications in Microelectronic Device Fabrication, Taylor Francis Group, New York 2006. 
[12] T. Hino, M. Harada, Y. Yamauchi, Y. Hirohata, Surf. Coat. Technol. 108-109, 312 (1998).

[13] F.-W. Chang, T.-H. Liou, F.-M. Tsai, Thermochem. Acta 354, 71 (2000).

[14] O.C. Hellman, N. Herbots, O. Vancauwenberghe, Nucl. Instrum. Methods Phys. Res. B 67, 301 (1992).

[15] R. Hezel, N. Lieske, J. Electrochem. Soc. 129, 379 (1982).

[16] S. Taniguchi, T. Shibata, K. Nakamura, L. Xianghuai, Z. Zhihong, H. Wei, Z. Shichang, Mater. Sci. Eng. A 121, 519 (1989).

[17] R. Hayakawa, T. Yoshimura, A. Ashida, T. Uehara, N. Fujimura, Thin Solid Films 506-507, 423 (2006).

[18] R. Perera, A. Ikeda, R. Hattori, Y. Kuroki, Thin Solid Films 423, 212 (2003).

[19] J.R. Troxell, J. Electr. Mat. 14, 707 (1985).

[20] R.P. Netterfield, P.J. Martin, W.G. Sainty, Appl. Opt. 25, 3808 (1986).

[21] J. Petruzello, T.F. McGee, M.H. Frommer, V. Rumennuk, P.A. Walters, C.J. Chou, J. Appl. Phys. 58, 4605 (1985).

[22] S. Salimian, C.B. Cooper, M.E. Day, J. Vac. Sci. Technol. B 5, 1606 (1987)

[23] K.D. Allen, H.H. Sawin, A. Yokozeki, J. Electrochem. Soc. 133, 2331 (1986).

[24] F.M. El-Hossary, N.Z. Negm, S.M. Khalil, A.M. Abd El-Rahman, Thin Solid Films 405, 179 (2002).

[25] S.H. Mohamed, A. Anders, Thin Solid Films 515 , 5264 (2007)

[26] P. Alpuim, P. Ferreira, V. Chu, J.P. Conde, J. Non-Cryst. Solids 299-302, 434 (2002).

[27] M. Vila, C. Prieto, R. Ramirez, Thin Solid Films 459 , 195 (2004).

[28] H. Miyazaki, T. Goto, J. Non-Cryst. Solids 352, 329 (2006).
[29] A.M. El-Naggar, A.M. Al-Dhafiri, Opt. Laser Technol. 41, 295 (2009).

[30] O.S. Panwar, C. Mukherjee, R. Bhattacharyya, Solar Energy Mater. Solar Cells 57, 373 (1999).

[31] J. Mullerova, S. Jurecka, P. Sutta, Solar Energy 80, $667(2006)$

[32] R. Ayouchi, R. Schwarz, L.V. Melo, R. Ramalho, E. Alves, C.P. Marques, L. Santos, R. Almeida, O. Conde, Appl. Surf. Sci. 255, 5299 (2009).

[33] A. Parashar, S. Kumar, J. Gope, C.M.S. Rauthan, P.N. Dixit, S.A. Hashmi, Solar Energy Mater. Solar Cells 94, 892 (2010).

[34] H. Rinnert, M. Vergnat, G. Marchal, A. Burneau, J. Lumin. 80, 445 (1999).

[35] T. Ohta, R. Kumar, Y. Yamashita, H. Hoga, J. Vac. Sci. Technol. B 12, 585 (1994).

[36] S.V. Deshpande, E. Gulari, S.W. Brown, S.C. Rand, J. Appl. Phys. 77, 6534 (1995)

[37] S. Guruvenket, J. Ghatak, P.V. Satyam, G. Mohan Rao, Thin Solid Films 478, 256 (2005).

[38] A. Straboni, L. Pichon, T. Girardeau, Surf. Coat. Technol. 125, 100 (2000).

[39] V. Verlaan, A.D. Verkerk, W.M. Arnoldbik, C.H.M. van der Werf, R. Bakker, Z.S. Houweling, I.G. Romijn, D.M. Borsa, A.W. Weeber, S.L. Luxembourg, M. Zeman, H.F.W. Dekkers, R.E.I. Schropp, Thin Solid Films 517, 3499 (2009).

[40] D.R. Ciarlo, Biomed. Microdev. 4, 63 (2002).

[41] L.J. Fernaández, E. Berenschot, J. Sesé, R.J. Wiegerink, J. Flokstra, H.V. Jansen, M. Elwenspoek, Electron. Lett. 41, 124 (2005).

[42] K.J. Winchester, J.M. Dell, J. Micromech. Microeng. 11, 589 (2001) 